\title{
Economic Recession In Nigeria: An Important Risk Factor For Suicide
}

\author{
Emmanuel U. Asogwa (Ph.D.) \\ Department Of Human Kinetics Anf Health Education \\ University Of Port-Harcourt, Nigeria \\ John. O. Onyezere (Ph. D.) \\ Department Of Human Kinetics And Health Education \\ University Of Port-Harcourt
}

\begin{abstract}
There was a general belief and assumption that Nigerians so much love life that none of its citizens can ever think of taking his own life. This might have been responsible for the World Values Survey Report in 2003, which ranked Nigerians among the happiest people in the world, and the $6^{\text {th }}$ happiest people in Africa, and $95^{\text {th }}$ in the world by the United Nations (UN) in spite of the glaring challenges confronting them. However, these good stories may have been faulted and the general belief and assumption dispersed by the worrisome high rates of suicide in Nigeria few months into economic recession, which started in the first quarter of 2016. This development is strange to Nigerians, and in view of this, there are grounds to consider an association between economic recession and increased suicide rates. This study, therefore, intends to establish that economic recession is an important risk factor for suicide, and recommend measures to prevent recession-induced suicide.
\end{abstract}

Key words: Economic recession, and Suicide

\section{INTRODUCTION}

Nigeria has witnessed a rapid increase in suicide occurrence in recent times, shortly few months into economic recession in the country in the first quarter of 2016. The disturbing rise in suicide cases in the nation has attracted attention from many quarters, including national assembly. In June 2017, the Nigerian Senate raised alarm over the rising spate of suicides and suicide attempts in the country. The senators wondered why the sudden rise in suicide cases in Nigeria, a country that was ranked $78^{\text {th }}$ happiest nation in the world and $4^{\text {th }}$ in Africa in the 2015 World Happiness Report; and the 95 th happiest nation from 155 countries, according to another report published in March, 2017 (Ojiabor, 2017). This development calls for a probe into relationship or correlation between economic recession and suicide occurrence. In her reaction to this problem, Senator Oluremi Tinubu, representing Lagos central zone in the $8^{\text {th }}$ National Assembly, noted that societal ills, economic difficulty and crime rates, which are prevalent in Nigeria are sufficient to send anyone over the edge. This followed reports of suicide cases on mass media on daily basis happening in different parts of the country. For instance, Nigeria Police Report in Lagos State shows that in a week, four suicide cases were reported in Lagos alone (Punch, March 21 \& 25, 2017) added to many other cases of suicide in different parts of the country.

Suicide means an act to end one's own life intentionally, either by self-inflicted or indirect means of assistance of another person, or inaction of the individual, when he or she knows that his or her inaction will cause his or her own death (Asogwa, 2012). The term 'suicide' connotes a deliberate act to end one's own life. Suicide, whether it is complete or incomplete (attempt), or as the sequential outcome of mental disorder, economic hardship, interpersonal 
relationship problem, physical pain, or combination of these, represents a tragic event. It brings to the survivors (family, friends, or neighbours) anguish, shame and probably, selfblame or self-reproach. Suicide, usually, comes as a total surprise to the relations, and associates of the deceased, creating an aura of mystery, and giving rise to wild speculations as to antecedent causes and to queries as to whether the event might have been prevented, either by the family, friends, or the society . However, the decision to commit suicide is usually not a spontaneous act, but one that evolves slowly over a period of months or years, during which the person either gives clues or openly declares such intent (Asogwa, 2016). Within the period, one may display or exhibit warning signs and symptoms, which can lead to possible management or prevention of the situation. According to Stoppler (2009), seventy-five per cent of those who die by suicide do display some suicide "warning signs" which researchers describe as "cry for help" (Okafor \& Okafor, 1998).

Economic recession is a period of general economic downturn, that is, decline in gross domestic product (GDP) for two or more consecutive quarters (Gunnell \& Chang, 2016). It is accompanied by increases in unemployment, job losses, reduction of goods produced in a market, which reduces the number of people who are employed and increases the prices of goods in the market. In times of economic recession, the financial noose are tightened around the neck of individuals and families, and many have sad tales to tell, jobs are lost, contract/job opportunities waned, while free flow of cash ceased by the day.

There exists a large of literature that has investigated the relationship between economic recession and suicide across many different countries and time periods. In 2007 and 2008, the "Great Recession" occurred which was an economic recession of global proportion and was the most severe of its kind since the Great Depression of the 1980s. Studies showed that suicide rates increased rapidly, for example, in the United States (Granudos \& Diez-Roux, 2009) during the Great Depression and in Korea (Watts, 1998) and Japan (Chang, Gunnell, Sterne, Lu, \& Chang, 2009). Case-control and longitudinal cohort studies conducted in a variety of countries, suggest that economic decline increases the incidence of self-destructive behavoiur (Gunnell \& Chang, 2016). The cross-national studies show that the impact of recession on suicide rates differs from country to country; these differences are in part due to varying levels of recession and job loss and also to differences in baseline economic conditions, as well as, welfare systems and policy responses to support those affected.

Based on existing evidence, Nigerians have started to observe and feel seriously debris of economic recession. This debris includes layoff/job losses, business closures, economic shock, contraction, downturns, slow down, financial reverses, unemployment, health spending cuts, increased general morbidity and mortality, psychological and behavioural morbidity, such as depression, anxiety, substance use and abuse, violent behavoiur and suicide. In spite of the dominant presence of these suicide catalysts in Nigeria presently, there are no appropriate responses of the government and other stakeholders to mitigate the impact of recession on the people. Access to mental health specialists is expensive and almost out of reach of the poor and middle class in Nigeria. The people face deprivations of basic necessities of life, such as food, housing, security, fair treatment and justice. All these actions or inactions of stakeholders, whose responsibility it is to ensure social and health wellbeing of the citizenry may have been responsible for the exponential rise in suicide rate that has assumed epidemic proportions, just few months into economic recession in Nigeria.

Suicide is preventable. Recognition of suicide predictors and warning signs is the first step in preventing suicide. Silverman and Maris (1995) stated that prevention of suicide is predicated 
on the prediction of suicide. Many other suicide prevention measures have been suggested by researchers. These measures include; modification of social and economic conditions such as reduction of poverty, violence, and promotion of healthy lifestyles; provision of social support; assessment of family members who may be influenced by the suicide and suicide attempts to attempt suicide themselves; and improvement of allocation to health sector (Sher, 2007; Asogwa, 2012). As it is, often the case, in recession period, expenditure for health and welfare services is diminished in order to allocate investments to other areas. These cuts may lead to a restructure of the roles and functions of the health care personnel, resulting in deterioration of the quality of services provided. This, in turn, may increase the burden of illness and deepen the social inequalities, leading to poverty and social deprivation. In relation to Nigeria, there should be health reform that should emphasize on the field of prevention and early intervention, and redistribution of national resources through social spending for the common good of the masses. Okafor and Okafor (1998) stated that prevention of suicide holds the premise of providing more good to more people, more effectively and more efficiently.

\section{THE CONCEPT OF ECONOMIC RECESSION}

A recession is a general downturn in any economy. According to the National Bureau of Economic Research (NBER), recession is a significant decline in economic activity spread across the economy, lasting more than a few months, normally visible in real Gross Domestic Product (GDP), real income, employment, industrial production and wholesale-retail sales (Corcoran, Griffin, Arenson, Fitzgeral, \& Perry, 2015). Recession can also be described as when business ceases to expand, the GDP diminishes for two consecutive quarters, the rate of unemployment rises.

Economic recession is characterized by a number of happenings. These include: a decline in GDP for two or more consecutive quarters; economic downturn, contraction, slowdown, financial reverses; layoffs and job losses; reduction of goods produced in the market; reduction in the number of people employed; high rates of unemployment; increases in the price of goods and services; drop in the stock market; reduction in spending; and business and home foreclosures. Generally, a recession is less severe than depression.

According to experts, there are several causes of economic recession, which include:

- Slowdown of economic activities due to war, unrest, or insecurity;

- Credit crunch;

- Wage price control- fixing workers' wages and salaries by the government;

- Poor economic planning and politics due to wrong and weak economic policies, programmes and responses of the government in power. The 1981 recession in United States is thought to have been caused by the tight-money policy by Paul Volcker, Chairman of Federal Reserve Board before Ronald Reagan took office.

- Mass unemployment and general loss of confidence on the government;

- Reduced consumers' confidence. If consumers believe the economy is bad, they are less to spend money.

- Fall in aggregate demand, fall in wages and income;

- High interest rate discouraging investors;

- Accumulation of debt servicing, especially foreign debts;

- High inflation leading to low purchasing power;

- Stock market declines;

- Paradoxes of thrift and deleveraging;

- Liquidity trap, among others (Gunnell \& Chang,2016; Hawton, 2013) 
A liquidity trap is a Keysnesian theory, that a situation can develop, in which interest rates reach near zero (zero interest-rate policy), yet do not effectively stimulate the economy. The U.S 2009 recession and Japan's recession last decade were described as liquidity traps.

\section{RELATIONSHIP BETWEEN ECONOMIC RECESSION AND SUICIDE}

Findings of studies have established that economic difficulties such as, economic decline, slowdown, hardship, downturn, recession, and depression increase incidences of selfdestructive behaviors, including suicide. According to Hawton (2013), the association of economic recession and suicide is clear and positive. The theories of Henry and Short's Countercycle and Ginsberg's procyclical tend to explain why recession increases suicide deaths. Henry and Short's countercyclical theory propounded in 1954 states that suicide rates tend to rise during times of economic 'busts', and fall during economic 'booms'. It is based on the frustration-aggression premise- the idea that during business contractions, some persons of high economic position commit suicide due to their loss of status. According to Ginsberg's procyclical theory (1996), suicide arises from the dissatisfaction of individuals, which is directly related to the discrepancy between the actual reward of an individual and his level of aspiration. As the economy expands, the prosperous economic environment pushes aspirations up at a rate faster than the rewards and this resulting disparity triggers suicide.

A Nigerian consultant psychiatrist and Coordinator of Suicide Research and Prevention Initiative (SURPIN) and Staff Emotional Care Services (SECS), Dr. Rapheal Emeka Ogbolu states that financial status is one of the things that can make a person to commit suicide. Azoma (2017) concurs that during the global economic recession, there was lot of suicide worldwide.

According to Asogwa (2015), the early scholars had noticed relationship between economic factors and fluctuation of suicide rates. In his work, Dan Douglas Wallis in the University of British Columbia reported that in Britain, United States, France and Germany from 1814 to 1913, he noted that Thomas Swaine Dorothy wrote that it was surprising that the greatest number of suicides occur during business depression, and Walter Hurlburt also, within the period of 1916 to 1920, observed a certain degree of causal relationship between prosperity, depression and the suicide rate. Hurlburt noted that between 1902 and 1925, the suicide rate revealed a tendency to decline in years of prosperity and to advance in the years of depression. The suicide rate registered was in its greatest increase in the years of acute economic distress and in its greatest decrease during the period of abnormal prosperity.

Hawton (2013) stated that research shows that it has been known that economic conditions can influence suicide rates. He gave instances that the depression of the 1920s to early 1930s was associated with marked rises in suicide, especially, in men, which, paralleled increases in unemployment; and the Asian economic recession (1997-1998) was followed by rising suicide rates. Corcoran et al. (2015) also noted increased suicide during the great depression in USA, and during the economic crises of late 1990s in Russia and South East Africa

Contemporary studies consolidated the findings of the early scholars on the relationship between economic distress or recession and suicide increases. Gunnell and Chang (2016) in their study established an impact of the 2008 global economic downturn on suicide by comparing numbers of suicides in 53 countries in 2009, with numbers of expected on the basis of 2000-2007 trends. They noted that excess number of suicide occurred in many of the countries, especially, in Europe and the US, particularly in men and young people. According to Chang et al. (2009), and Stuckler, et al.(2014), several researchers estimated that the Great Recession was associated with at least 10,000 additional economic suicides between 2008 and 
2010 in North America and Europe. Barr, Taylor-Robinson, Scott- Samuel, Mickie, and Stuckler (2012) estimated that the Great Recession in United Kingdom led to about 1000 excess suicides in a year; 846 among men and 155 among women. The analysis indicated that increases in male unemployment were associated with about two fifths of these rises in suicides among men in England during the recession. More so, Norton (2015) reported that twelve studies investigated the impact of the Great Recession on suicide rates, ten of the studies found evidence for association between the recession and suicide rates

From the findings of both the early and contemporary research, and observations and experiences in the countries passing through recession in recent times, it is becoming increasingly apparent that financial or economic difficulties induce suicide completions and attempts. It is being realized that the greatest number of suicides occur during business failure and economic hardship.

In the modern times, researchers have identified three major groups of economic-suicide risk factors, which include; economic hard times, global financial crisis and monetary incentives (Chen, Choi, Mori, Savada, \& Suguno (2009). According to Kasterbaum (1991), economic hard times are associated with an increase in the suicide rates. This is because economic hard times result in unavailability of jobs, loss of jobs, and different forms of financial reverses, each of which has been associated with suicide. American Association of Suicodology (2009) corroborates that bad economics are associated with increased suicide rates, especially, those recessions with marked elevations in negative outcomes, such as job losses and home foreclosures.

Gunnell and Chang (2009) state that whilst rises in unemployment account for some of the recession-associated increase in suicide, other factors such as increased levels of debt, house repression, relationship difficulties, alcohol misuse, pressures on those remaining in work, and job security, government austerity measures introduced in response to recessions also play a role. Financial strain has been reported as mediating the association between unemployment and minor psychiatric morbidity and suicide.

Findings of studies show that national rise in unemployment is always followed by an increase in suicide rate, which is reversed when the employment situations brighten (Garrison, 1992). This suggests that in Nigeria, where rise in unemployment in recent times is unprecedented, and hundreds of workers lose their jobs on daily basis; increasing rise in suicide rates is highly probable, as long as recession lasts in the country. The high rate of unemployment in the country between 2016 and 2017 is disturbing. For example, more than 8,630 bank workers lost their jobs in 2017 alone. Nigeria's National Bureau of Statistics [NBS] (2017) pegs the unemployment rate in Nigeria at 14.2 per cent in the last June, 2017. The NBS disclosed that the rate rose from 13.9 per cent recorded in the preceding quarter of the year under review. It also noted that as the number of unemployed people in the economy is growing, the number of underemployed people is also rising, attributing the development to negative economic growth recorded by the nation in 2016.Garrison (1992) reported that those findings at both national and local levels generally have associated unemployment with high rates of suicide. Wasserman (1992) also discovered significant statistical correlation between growth of suicide rate and increasing unemployment rate

Debt is another financial risk factor for suicide. Reports of Tata Institute of Social Sciences in Mumbai revealed that 150,000 debt-ridden farmers in India committed suicide in order to escape the burdens of their debts (Tata Institute of Social Sciences, 2009; Asogwa, 2010). The similar events are playing out in Nigeria, few months into recession. For instance, on March 25, 
2017, a national daily, Punch Newspaper, reported two incidents of attempted suicides of two women in a week in Lagos, who were said to be heavily indebted. One of them, Mrs. Ogunyinka said that she wanted to take her life because she owed a micro-finance bank a sum of N150,000.00.

Chen et al. (2009) theorized that some borrowing systems could result in suicidal acts by borrowers, because of excessive pressure. They pointed out that when a borrower fails to repay his debt, the informal enforcement mechanism may put too much pressure on him in the form of stigma, social penalty, or forcing the borrower to commit suicide. West (2003) observed that many people in Japan, for instance, seem to believe that committing suicide lessens the burden on family members, as opposed to having them live with a debtor. However, few studies reported negative relationship between economic recession and suicide rates. Norton (2015) cited some findings that showed suicide rates decreased in Sweden and Finland in 1990s when the both countries suffered from economic. The Sweden and Finland experience was attributed to their robust social protection programmes as well as active labour market programmes, which assisted the unemployed in funding and acquiring work. However, these few cases do not undermine the weight of evidence that economic recession increases suicide rates

Many different studies, both the early and contemporary have separately implicated economic recession with an increase in suicide rates. The present spate of suicide in Nigeria, some months into recession, is a confirmation of these findings of studies. This also suggests that economic recession generally predicts suicide, and Nigeria may continue to experience increasing rise in suicide occurrence as long as recession lasts, unless, urgent measures are put in place to prevent the tragic act of suicide due to the economic hardship. Although, economic recession tends to increase suicide, the strength of the association varies among countries, and there is evidence that risks can be mitigated by strong social support and employment programmes. According to Gunnell and Chang (2016), controlling suicide resulting from economic recession requires preventing economic recession, or controlling the effects of recession on individuals and families.

It has been observed that he impact of high profile economic recession in high and middle income countries, such as the Great Recession, the post-communist period in Russia (19911994) and the Asian Financial Crisis (1997-1998/9) have been the focus of recent research rather than in low income countries, like African countries. The relationship between economic recession and suicide in low income countries remains unclear. Since, these studies have mostly been carried out in high and middle income Western and South-East countries, research in low income countries like Nigeria is needed.

\section{THE SITUATION IN NIGERIA}

It is becoming evident that suicide act is now being embraced by many Nigerians, supposedly, as a way out of their travails, and most recently, the present harsh economic situation in the country. Many suicides happen in the country on each passing day. Guardian Magazine (March, 2017) reported that few months into recession, in each passing week Nigerians in their numbers take their lives, but only few of these suicide and attempts are reported.

Few of such cases reported in only two states in the western Nigeria between January and February, 2017 according to Guardian's report include: a 35-year-old medical doctor, Alwel Orji, who jumped into the Lagos lagoon in the third mainland bridge and died; on the same day and at the same spot, a woman jumped into the lagoon to commit suicide, but was rescued; a 
500-level Urban and Regional Planning undergraduate of Ladoke Akintola University of Technology (LAUTECH), Ogbomosho, Adesoji Adediran, hanged himself inside his hostel room; a 19-year- old student of Babcock University Ilishan-Remo, Ogun State, Verishima Unokyur, committed suicide in his parent's home in Mafoluku area of Oshodi, Lagos; a 44-year-old bank manager in Lagos, killed himself because he was under pressure from his bank over loan repayment, among other numerous cases reported by mass media houses on daily basis.

The available suicide statistics from the psychiatric hospitals in Kware, Sokoto State, Ilorin, Yaba, Uselu in Edo State, Maiduguri, Eket, Enugu, Aro, and Abeokuta in 2016 are frightening, alarming, and strong indication that recession induces suicide. According to the statistics, suicide rates in 2016 were significantly higher than the previous years. In Sokoto State, total number of suicide patients in 2015 was about 60,000, and in 2016 the number jumped slightly above 93,000.At the Federal Neuro-Psychiatric Hospital in Yaba, 25,000 patients were seen in 2015 compared to about 53,000 patients in 2016.Similar increases in suicide rates in other psychiatric hospitals were observed. These numbers of suicide patients from only two hospitals out of hundreds of such facilities exclude numerous suicide cases handled in traditional and prayer homes and houses, which are not usually reported. According to Guardian (March, 2017), all the psychiatrists in the surveyed hospitals unanimously, yet, separately arrived at the same conclusion that the economic downturn and hardship have affected the finances of citizens, and a major factor responsible for the increased cases of mental illness, which is an important risk factor for suicide.

The surge of suicides and attempts in Lagos in particular and many other reported and unreported cases that happened across the nation in general, is troubling and of a great concern in a country, where suicide rates were usually low. A few studies in Nigeria have looked at rates of suicide. Reports of Nigeria Police Force showed seven states with high suicide rates; which include Ogun State with the highest rate, followed by Lagos, Ebonyi, Delta, Oyo, Ondo, and Kano States. The Head of Psychiatry Department, Lagos University Teaching Hospital, Professor Olatunyi Aina and Dr. Raphael Ogbolu, the Coordinator of Suicide PreventionServices called The Suicide Research and Prevention Initiative and Staff Emotional Care Services (SURPI/SECS, Nigeria) separately revealed that during lifetime, about three per cent Nigerians have had thoughts about ending their lives, one per cent will plan on how to kill themselves, and just under one per cent will carry out an attempt to kill themselves. WHO (2011) also states that, approximately one million people die by suicide each year, and for everyone who dies by it about twenty more have attempted it.

The current trend of suicide cases in Nigeria may have increased the rate of suicide of the country as recorded in the WHO (2012) Suicide Statistics, which show that an estimated 6.5 people kill themselves each year in Nigeria per 100,000 people compared to 9.1 in Germany, 12.1 in the U. S., and 19.5 in Uganda. It further stated that up to one million people die by suicide every year, despite that most cases are not being reported. Eighty-five per cent of suicide occurs in Low and Middle Income Countries (LMIC), of which Nigeria is one. Therefore, these emerging reports of high and significant rising of suicide rates in Nigeria in recent years should be a disturbing, troubling and grave public health problem; hence, urgent attention of government and other stakeholders is highly needed to curb this potentially preventable problem.

\section{IMPACT OF ECONOMIC RECESSION ON INDIVIDUALS}

Economic recession has been implicated with a lot of both social and health problems. It leads to increased unemployment and indebtedness. Productivity tends to fall in the early stages of a recession then rises again as weak firms close (Norton, 2015). Social effects include poor or 
low standard of living, violence, robbery, prostitution, and other social vices (Khang, Lynch, \& Kaplan, 2005). Another secondary impact is in the area of relationship. Parents who find themselves struggling financially may take several minimum wage jobs working for long hours to try and make ends meet leaving less time at home. This may erode important supports and the time they spend with family and result in increased risk for their children and perhaps aging parents.

Many health problems have been associated with recession. Economic stress may lose health care coverage, and/or the ability to pay for expensive deductibles or medications, which may hinder access to mental and other health care when treatment becomes necessary. Studies have linked some health problems to recession, such as cardiovascular diseases, digestive diseases, poverty-related diseases, mental illnesses, alcoholism, smoking and drug abuse (Stuckler, et al., 2009)

\section{PREVENTION MEASURES FOR ECONOMIC RECESSION-INDUCED SUICIDE}

Suicide is a global potentially preventable public health problem. Gunnell and Chang (2016) suggest that controlling suicide resulting from economic recession requires preventing economic recession, or controlling the effects of recession on individuals and families. According to them, based on existing evidence, appropriate responses to mitigate the impact of recession on suicide might include active labour market programmes, generous unemployed benefits, responsible media reporting, debt relief, adequate funding of community support agencies, and preserved spending on mental health services.

Some other ways of mitigating the effect of recession have been suggested by scholars (Gunnell \& Chang, 2016), which could invariably prevent recession-induced suicides. These include:

- Avoid living a life to satisfy other's expectation at the expense of your income or convenience.

- Avert social functions that will adversely affect your finances in items of distance and the content of the programme. Appropriately, communicate to those who ask for financial favour that things are no longer the same and stop pretending at your expense.

- Plan only on funds at hand.

- Purchase only items that are considered as necessities and postpone all luxurious articles.

- Except, it is affordable, avoid all ceremonial uniforms or any clothes made mandatory during ceremony.

- Re-evaluate recurrent expenditure pattern, like children school fees, and effect necessary changes if need be.

- If the regular food in the house is becoming more expensive, try alternative that are cheaper.

- Applicants should take any available job even when such job is below the dream job.

- Avoid taking unnecessary risk in the work place or business that increases the possibility of retrenchment or loosing client.

- Be more committed to your profession, job or business than ever.

- Many friendly loans will be irrecoverable. Therefore, avoid lending money that will affect your financial stability if not received on time.

- Individual or families living in rented apartment with unused room(s) should get smaller accommodation.

- Exercise more frequently to minimize constant requirement of drugs. And learn to trek short distances as it will improve health and relieve avoidable small expenses. 
Social protection programmes may potentially act as a buffer against negative socioeconomic effects of recession (Norton, 2015). Developing social protection intervention would require a better understanding of the group who are likely to be more exposed to the negative effects of an economic recession. For example, if increased unemployment was clearly demonstrated to mediate the relationship between economic recession and suicide rather than indebtedness, active-return-to- work schemes may play a more relevant role in social protection spending than debt relief programmes.

Identification and recognition of suicide warning signs is another very effective way of preventing suicide. Many studies have stated that prevention of suicide is predicated on the prediction of suicide (Asogwa, 2012; Silverman \& Maris, 1995). The American Association of Suicidology (2009) has developed a way to help identify the warning signs of suicide in individuals, coined IS PATH WARM, which stand for I - Ideation, S - Substance abuse, P Purposelessness, A - Anxiety, T - Trapped, H - Hopelessness, W - Withdrawal, A - Anger, R Recklessness, and M - Mood change. Stoppler (2009) reveals that seventy-five per cent of people who commit suicide exhibit warning signs. And Caruso (2009) adds that when an individual displays any four of these serious signs, for two weeks, it shows that there is impending suicide, and urgent attention or help is needed to save a life.

Primary prevention of suicide, which means reduction of new cases, is considered the best method of preventing suicide. The primary prevention of suicide requires effective treatment of psychiatric disorders, especially mood disorders; modification of social, economic and biological conditions, such as reduction of poverty, violence, divorce rate, and promotion of healthy lifestyle (Sher, 2004).

Identification and enhancement of suicide protective factors could be a good prevention measure against suicide. Association of Psychiatrists in Nigeria (APIN) identifies some factors against the development of suicidal behaviours, as the need to develop resilience (the ability to cope with adverselife events and adjust to them), a sense of personal self-worth and selfconfidence, effective coping and problem-solving skills and adaptive help-seeking behavior (Guardian, 2017). Some other suicide protective factors or deterrents include: children in the home (except among with post-partum psychosis); deterrent religious beliefs; life satisfaction; reality testing ability; positive coping skills; positive social support; and positive therapeutic relationship.

Improvement of health care services, especially, mental health care would in no small way help in reducing number of cases of suicide. Health care reforms and improvement should emphasize on the field of prevention and early intervention, and flexible systems that tailor health care services to the community needs. More so, there should be redistribution of national resources through social spending for the common good of the masses based on the slogan "from each according to his ability, to each according to his needs", and increased budgetary allocations to primary health care and social welfare services.

Scholars differ on criminalization of suicide as a suicide prevention measure. African Journal of Criminalization and Justice Studies [AJCJS] argued that criminalization of suicide and suicidal behaviours, ubiquitous anti-religious belief and mortuary practices that discourage selfinflicted deaths are responsible for low rate of suicide in African countries ( $0^{\prime}$ Connor \& Pikis, 2016). The Nigerian Federal Law criminalizes suicidal behavior. According to Nigeria Penal Code, Chapter 27, Section 327: "Any person who attempts to kill himself is guilty of misdemeanor and is liable to imprisonment for one year". Nigerian Law also criminalizes abetment of suicide as Chapter 27, Section 326 states; "Any person who (1) procures another 
to kill himself; or (2) counsels another to kill himself and hereby induces him to do so; or (3) aids another in killing himself; is guilty of a felony and is liable to imprisonment for life (Okafor \& Okafor, 1998).In practice, it is only attempted suicide that is a crime in Nigeria and not completed suicide act, because there is no actual persecution against those who committed suicide.

However, a number of health professionals and non-governmental organizations in the field of suicide prevention condemn criminalization of suicide as a way of deterring people from committing suicide. They argue that those people who attempt suicide need psychological counseling, medical help or material assistance rather than judicial punishment ( $0^{`}$ Connor \& Pikis, 2016). According to them, for anti-suicide law to have the anticipated deterrent effect, it is essential that citizens be aware of the illegality of attempting suicide. It is not known how many suicidal persons have been constrained from carrying out a suicidal act because of their awareness of extant legislation that criminalizes suicidal behviour.

Many suicide prevention programmes have been suggested by different scholars, but, according to O'Connor, \& Pikis (2016), any programme aimed at the prevention of suicide must include in its broad outline at least five measures, such as:

- The immediate reporting of suicides and attempts to responsible public health officers;

- The provision of immediate medical attention;

- Psychiatric assessment and treatment where indicated for a defined period of time;

- The recognition that the suicide gesture is a device to gain sympathy or attention, and the insight to realize that these should be accorded;

- A follow-up service by the social service department of the hospital and the public health unit in the community;

- Stricter controls over the prescribing of lethal and addictive drugs;

- Less sensationalistic approach by the press in the reporting of suicides and suicide attempts.

\section{CONCLUSION}

The association between economic recession and increase in suicide rates is clear and positive. Recession decline increases the incidence of self-destructive behavior, including suicide. Economic recession leads to lay off or job loss, economic shock, business closure, health spending cuts, financial downturns and reverses; diminishes expenditure of health and welfare services; causes high inflation, unemployment, hardship; and slows down domestic products. And all these debris of recession have been associated with inadequate health, anxiety, violence, self-harm, risky behavior, depression and suicide.

Reports of studies and experience have clearly shown that economic recession is a strong predictor of suicide. The increased suicide rates observed in Nigeria within the period of recession in 2016 and 2017 lend credence to the fact that recession predicts suicide.

\section{RECOMMENDATIONS}

Although economic recession increases suicide rates, but responses of government and other stakeholders may limit the extent. Government can respond to recession by adopting expansionary macro-economic policies such as increasing money supply, increasing government spending and decreasing taxation. Recession-induced suicide could be prevented by addressing those factors that cause recessions such as tight-money policy and inadequate positive responses of government, stock market decline, liquidity trap, reduced consumers' 
confidence, and reduced real wages. More so, the country's social security system should be more comprehensive so that recession will not result in the increased rate of suicide

There should be improvement on mental health to ensure early detection, diagnosis, treatment of depression and other depression-related disorders, psychiatric disorders, and self-harm and suicide tendencies. More so, public health programming should be tailored to individual community needs in terms of patterns of allocations methods and a way of working.

Government agencies and voluntary organizations should mount health, social and welfare programmes and packages that will develop in people the ability to cope with adverse life events and adjust to them, a sense of personal self-worth and self-confidence, effective coping and problem-seeking skills and adaptive help-seeking behaviour, as they are often considered to be suicide-protective factors. In this sense, these agencies at all levels (local, state, national) should embarked on extensive social welfare packages for the masses to overcome extreme poverty, desperate situation of the majority punctuated by periods of lacks, and compounded economic recession in the land and the insensitivity of government to the plights of people. Other suicide-deterring belief and practices among people, such as, anti-suicide religious beliefs, mortuary practices that discourage self-inflicting death, availability of social support to despairing individuals, and limited access to potentially lethal methods of suicide, should be encouraged and maintained.

The primary health care team should be encouraged to play their role which is detecting suicidal thoughts in high risk groups such as the unemployed and providing patients with the appropriate counseling, treatment or referrals

There should public enlightenment to create awareness on how to identify warning signs of suicide in individuals coined, IS PATH WARM, so as to be able to offer necessary help to friends, neighbours, or family members contemplating suicide. There should be also awareness on the illegality of attempted suicide and the extant legislation that criminalizes suicidal behaviour

\section{References}

American Association of Suicidology [ASS (2009). AAS statement on the economy and suicide. http://www.suicidology.org/web/guest/current-research

Asogwa, E. U. (2010). Suicide: an unaddressed social and health problem in Nigeria. Nigerian Journal of Functional Education, 6 (1), 83-96

Asogwa, E. U. (2012). Strategies for prevention of suicide. Issues of Physical Training and Health Education: A Book of Reading in the Honour of Brigadier I A Aderibigbe, 22-34

Asogwa, E.U. (2015). Knowledge and attitude towards suicide among university students in Enugu State. Unpublished Thesis Work, Faculty of Education. University of Port-Harcourt, Nigeria

Asogwa, E. U. (2016). Perceived factors responsible for low health care status of suicide in Nigeria. Journal of PortHarcourt JONAPHER-SD, 3, 44-52

Azoma, C. (March, 2017). Recession increases suicide cases- psychiatrists. The Punch, March 30, (6), 7.

Barr,B., Taylor-Robinson, D., Scott-Samuel, A., Mckee, M., \& Stuckler, D. (2012). Suicides associated with the 20082010 economic recession in England: time trend analysis. Hh=ttp://www.bmj.com/content/345/bmj.e5142

Caruso, K. (2009). Suicide warning signs. http://,suicide.org/suicide-warning-signs.html

Chang, S.S., Gunnell, D., Sterne, D.A., Lu, T.H., \& Cheng, A.T. (2009). Was the economic crisis 1997-1998 responsible for rising suicide rates East/Southeast Asia: a time-trend analysis for Japan, Hong Kong, South Korea, Taiwan, Singapore and Thailand? Social Science Medical, 68, 1322-1331

Chen, J., Choi, Y.J., Mori, K., Savada, Y., \& Suguno, S. (2009). Joint liability, borrowing and suicide. Center for International Research on the Japanse Economy, Discussion Papers. CIRJE-F-534, University of Tokyo. 
Corcoran, E., Griffin, E., Arensman,A.P., Fitzegeral, L., \& Perry, I.J. (2015).Impact of the economic recession and subsequent austerity on suicide and self-harm. International Journal of Epidemiology, 44 (3), 969-977

Garrison, Z. E. (1992).Demographic predictions of suicide: In R.W. Maris, A.L. Berman. Assessment and prediction of suicide. New York: The Guilford Press

Granudos, J.A. (2008). Macroeconomic fluctuations and mortality in positive Japan. Demography, 45, 323-342

Guardian Magazine (June, 2017). Worrisome, rising cases of suicide in Nigeria. https://guardian.ng/Saturdaymagazine/worrisome-rising-cases-of-suicide-in-Nigeria/Saturday/Magazine/Cover

Gunnell, D., \& Chang, S.S. (2016).Economic recession, unemployment and suicide. International Handbook of Suicide Prevention. United Kingdom: John Wiley and Sons Limited.

http://onlinelibrary.wiley.com/doi/10.002/9781118903223.chl6/summary

Harper, T.J., Charters, E.C.,Strumpt, S., Galead, I., \& Nandi, A. (2015). Economic downturns and suicide mortality in the USA. International Journal of Epidemiology, 44 (3), 956-966

Hawton, K. (2013). Economic recession and suicide. British Mental Journal (BMJ), 347, 15612.

Kasterndaum, R.J. (1991). Death society and human experience. New York: Macmillian Publishing Company

Khang, Y.H., Lynch, J.W., \& Kaplan, G.A. (2005). Impact of economic crisis on cause-specific mortality in South Korea. International Journal of Epidemiology, 34, 1291-1301

Nigeria's National Bureau of Statistics [NBS](2017). Rate of unemployment in Nigeria between 2016 and 2017. www.nigeriastat.gov.ng

Norton, K. (2015). Suicide and economy: what is the connection? World Journal of Psychiatry (WJP), 5 (2), 243254. http://www.ncbi.nlm.nih.gov/pmc/articles /PMC44734/table/T3/systematicreview of suicide in economic recession

O' Connor, C.R., \& Pikis, J. (2016). Suicide prevention. The International Handbook of Suicide Prevention. United Kingdom: Wiley and Sons Limited

Ojiabor. O. (June, 2017). Recession and increased rate of suicide in Nigeria. The Nation., June 14,2 (3978), 6. www.thenationonlineng.net.

Silverman, M.M., \& Maris, R. W. (1995). The prevention of suicidal behaviours: an overview. Suicide and LifeThreatening Behaviour, 25 (1), 10-21

Sher, I. (2004).Preventing suicide. http://qjmed.Oxfordjournals.org/content/97/10/677.full.

Sher, I. (2007). Preventing suicide. Quarterly Journal of Medicine, 97 (10), 677-680

Stoppler, M.C. (2009). Suicide warning signs. http://www.medicintent.com/suicide.article.html

Stuckler, D., Basu, S., Suhrcke, M., \& Mckee, M. (2009). The health implication of financial crisis: a review of the evidence. Ulster Medical Journal, 78, 142-145

Szanto, K., Kalmer, S., Hendin, H., Rihmer, Z., \& Mann, J.J. (2007). A suicide prevention programme in a region with a very high suicide rate. Archives of General Psychiatry, 64, 914-920

Tata Institute of Social Sciences (2009 July, 9). India farmers threaten mass suicide. The National,6, 1721

Okafor, J.O., \& Okafor, R. U. (1998). Emotional and mental health. Nsukka: Ralja Publishers

Wasserman, I. A. (1992). Economy, work, occupation and suicide. Journal of Black Psychology, 32, 320 -334

WHO(2006). Suicide prevention and mental health.

http://www.who.int/Mentalhealth.prevention/suicideprevent/en

WHO(2011).Updated suicide rates: the WHO suicide statistics. Geneva: Author

WHO (2012). International suicide statistics. http://www, suicide.org. international suicide.S... 